Bommelé, J., Schoenmakers, T.M., Kleinjan, M., Peters, G.J.Y., Dijkstra, A., Mheen, D. van de. Targeting hardcore smokers: the effects of an online tailored intervention, based on

\begin{tabular}{|l|l|}
\hline $\begin{array}{l}\text { Postprint } \\
\text { Version }\end{array}$ & 1.0 \\
\hline Journal website & http://onlinelibrary.wiley.com/doi/10.1111/bjhp.12256/abstract \\
\hline Pubmed link & $\underline{\text { https://www.ncbi.nlm.nih.gov/pubmed/28703470 }}$ \\
\hline DOI & $10.1111 /$ bjhp.12256 \\
\hline
\end{tabular}

This is a NIVEL certified Post Print, more info at http://www.nivel.eu

\title{
Targeting hardcore smokers: The effects of an online tailored intervention, based on motivational interviewing techniques
}

JEROEN BOMMELÉ1,2* TIM M. SCHOENMAKERS1,2,3, MARLOES KLEINIAN4, GJALT-JORN YGRAM PETERS5, ARIE DIJKSTRA6 AND DIKE VAN DE MHEEN1,2,7

1IVO Addiction Research Institute, Rotterdam, the Netherlands 2Erasmus Medical Centre, Rotterdam, the Netherlands 3NIVEL, Netherlands Institute for Health Sciences Research, Utrecht, the Netherlands 4Trimbos Institute, Utrecht, The Netherlands 5Faculty of Psychology and Educational Sciences, Open University, Heerlen, the Netherlands 6Faculty of Behavioural and Social Sciences, University of Groningen, the Netherlands 7Tranzo, School of Social and Behavioral Sciences, Tilburg University, the Netherlands

\footnotetext{
AbSTRACT

Objectives: Hardcore smokers have smoked for many years and do not intend to quit. They also seem unreceptive to information about smoking cessation. We developed a 30-min, tailored web-based intervention that includes motivational interviewing principles. It aims to increase hardcore smokers' intention to quit and their receptivity to information about smoking cessation.

Design: In a two-arm experiment, we compared outcome scores of the experimental intervention $(n=346)$ with those of a control intervention $(n=411)$.

Methods: Our main outcomes were receptivity to information about quitting, intention to quit, quitting self-efficacy, and interest in a subsequent online intervention. Our secondary outcomes were cigarettes smoked per day and quit attempts. All outcomes were measured directly post-experiment $\left(\mathrm{t}_{1}\right)$, after 2 weeks $\left(\mathrm{t}_{2}\right)$, and after 2 months $\left(\mathrm{t}_{3}\right)$.

Results: At $t_{1}$, hardcore smokers in the intervention condition were more receptive to information about quitting than controls. At both $t_{2}$ and $t_{3}$, those in the experimental group had reduced the number of cigarettes more than those in the control group. At $t_{2}$, but not $t_{3}$, more participants in the experimental group had reduced their cigarette consumption by at least $50 \%$ than among controls. We found no significant differences in intention to quit, quitting self-efficacy, interest in a subsequent online quitting intervention, and number of quit attempts.

Conclusions: The intervention increased hardcore smokers' receptivity to information about smoking cessation and decreased their cigarette consumption by
} 
Bommelé, J., Schoenmakers, T.M., Kleinjan, M., Peters, G.J.Y., Dijkstra, A., Mheen, D. van de. Targeting hardcore smokers: the effects of an online tailored intervention, based on

motivational interviewing techniques. British Journal of Health Psychology: 2017, 22(3),

about 1 cigarette per day. Although the results are positive, the clinical relevance may be limited. We recommend further developing this intervention for practical use in health care settings.

\section{STATEMENT OF CONTRIBUTION}

\section{What is already known on this subject?}

- Hardcore smokers have smoked for many years and do not intend to quit.

- There are currently no online interventions for hardcore smokers.

\section{What does this study add?}

- This study tested an online intervention for hardcore smokers.

- The intervention increased hardcore smokers' receptivity to information about quitting.

- It also helped to reduce the number of cigarettes per day.

\section{BACKGROUND}

Smoking is one of the leading causes of death and disease in the world (WHO, 2011). It is therefore imperative to find ways to promote smoking cessation. One group, the so-called hardcore smokers, seem particularly unlikely to quit smoking (Warner \& Burns, 2003). Hardcore smokers are people who have smoked for many years and have no intention-to-quit smoking (Costa et al., 2010). In 2012, 32\% of Dutch smokers could be considered 'hardcore', which equals to $8 \%$ of the Dutch general population (Bommelé et al., 2016). Compared to non-hardcore smokers, they have lower quitting self-efficacy (Sorg, Xu, Doppalapudi, Shelton, \& Harris, 2011) and tend to have dysfunctional beliefs about smoking (Bommelé et al., 2014). Dysfunctional beliefs are beliefs that prevent smokers from quitting, such as perceived benefits of smoking and perceived costs of quitting. As hardcore smokers have more such beliefs than non-hardcore smokers (Jarvis, Wardle, Waller, \& Owen, 2003), they may be particularly irresponsive to tobacco control interventions. Whereas many web-based smoking interventions have been developed for the general population (Civljak, Stead, Hartmann-Boyce, Sheikh, \& Car, 2013; Lemmens, Oenema, Knut, \& Brug, 2008; Walters, Wright, \& Shegog, 2006), no online interventions have been specifically developed for hardcore smokers. As hardcore smokers seem resistant towards information about quitting, it may be particularly difficult to convince them to quit smoking (Bommelé et al., 2015b; Warner \& Burns, 2003). As they might be unwilling to consider quitting, they need to become more open towards antismoking messages first (Prochaska \& DiClemente, 1982, 1983). We therefore developed and experimentally tested an intervention that aims to increase hardcore smokers' willingness to read such tobacco control messages. The intervention also aims to increase hardcore smokers' intention-to-quit smoking, quitting self-efficacy, receptivity to information about quitting, and interest in a subsequent online intervention.

\section{Increasing receptivity to information about quitting}

The first intervention component aimed to increase receptivity to antismoking information. According to the self-affirmation theory, everyone is motivated to perceive himself as a moral and competent person, who acts according to moral norms or his or her personal values (Steele, 1988). This sense of self-integrity may be threatened by health messages, because such messages suggest that smokers act 
Bommelé, J., Schoenmakers, T.M., Kleinjan, M., Peters, G.J.Y., Dijkstra, A., Mheen, D. van de. Targeting hardcore smokers: the effects of an online tailored intervention, based on

motivational interviewing techniques. British Journal of Health Psychology: 2017, 22(3),

inconsistently with personal or moral norms about healthy lifestyles (Harris \& Epton, 2009, 2010). Smokers therefore avoid or discard such antismoking messages.

Self-affirmations tackle such defensive responses to a threatening message (Epton, Harris, Kane, \& Van Koningsbruggen, 2015a; McQueen \& Klein, 2006). Selfaffirmations are positive reinforcements in another domain than the threatening message (i.e., other than smoking). They are believed to distract the self away from the loss of self-integrity. To tackle defensive responses in our intervention, we included the kindness questionnaire as a self-affirmation manipulation (Reed \& Aspinwall, 1998). In a previous study, we found that this manipulation is suitable for hardcore smokers (Bommelé et al., 2015b).

We used two other techniques to further increase receptivity to the messages in the intervention. First, we tailored responses of the digital trainer to participants' responses. Tailoring has been shown to increase the effectiveness of online interventions (Shahab \& McEwen, 2009). Second, we incorporated motivational interviewing techniques (Miller, 1983). Motivational interviewing has been used effectively in clinical settings (Lai, Cahill, Qin, \& Tang, 2010) and in another online intervention (Friederichs et al., 2014).

\section{Increasing intention to quit}

Intention-to-quit smoking is a major predictor of quit attempts (Vangeli, Stapleton, Smit, Borland, \& West, 2011). Its importance has been emphasized by the Health Belief Model (Rosenstock, Strecher, \& Becker, 1988) and the Reasoned Action Approach (Fishbein \& Ajzen, 2010). To increase intention-to-quit smoking, we developed one intervention component that aimed to improve attitude towards quitting (second intervention component) and one component that increases quitting self-efficacy (third intervention component). Attitude towards quitting and quitting self-efficacy are two determinants of intention to quit (Ajzen, 1991; Bandura, 1977; Fishbein \& Ajzen, 2010; Rosenstock et al., 1988), and both were important selfreported determinants of smoking cessation in two previous studies among hardcore smokers (Bommelé et al., 2014, 2015a,b).

The second intervention component aimed to improve attitude towards quitting by changing dysfunctional beliefs about smoking and quitting. In line with the Intervention Mapping protocol - a protocol for developing interventions (Bartholomew, Parcel, \& Kok, 1998; Bartholomew, Parcel, Kok, Gottlieb, \& Fernández, 2011), we selected a set of specific outcome beliefs from a previous focus group study on hardcore smoking (Bommelé et al., 2014). In that study, we identified six themes among hardcore smokers' perceived pros and cons of smoking and quitting. We used these themes as topics for this second intervention component. As hardcore smokers tend to perceive more pros of smoking and more cons of quitting than non-hardcore smokers (Bommelé et al., 2015a), it emphasized the cons of smoking and the pros of quitting.

\section{Increasing quitting self-efficacy}

The third intervention component aimed to increase quitting self-efficacy. Selfefficacy is theorized as a prerequisite of change in intention and behaviour (Ajzen, 1991; Bandura, 1977). Quitting self-efficacy is especially important for hardcore smokers, as they tend to have a lower quitting self-efficacy than non-hardcore smokers (Bommelé et al., 2015a; Sorg et al., 2011). Using the Intervention Mapping protocol (Bartholomew et al., 1998, 2011), we developed four video clips in which 
Bommelé, J., Schoenmakers, T.M., Kleinjan, M., Peters, G.J.Y., Dijkstra, A., Mheen, D. van de. Targeting hardcore smokers: the effects of an online tailored intervention, based on

motivational interviewing techniques. British Journal of Health Psychology: 2017, 22(3)

ex-smokers explained how they coped with difficult situations after quitting. In this third part of the intervention, participants viewed these video clips and elaborated on how they would cope with such difficult situations themselves.

\section{Current study}

We tested a tailored, web-based intervention for hardcore smokers. In a two-arm experiment, we compared outcome scores of the experimental intervention with those of a control intervention. Our main outcomes were receptivity to information about quitting, intention to quit, quitting self-efficacy, and interest in a subsequent online intervention. Our secondary outcomes are cigarettes smoked per day and quit attempts.

\section{METHODS}

\section{Participants}

Participants were recruited via an online panel (Survey Sampling International), which has about 11.5 million panellist in 103 countries. In the description of the study, we stressed that we were interested in their opinion about smoking only. We also emphasized that we would not judge their opinion and that they did not have to quit smoking during the study. We used a screener questionnaire to identify eligible Dutch hardcore smokers. Smokers were 'hardcore' if they (1) were 25-65 years old, (2) smoked every day, (3) smoked 15 cigarettes per day or more, (4) had no quitting attempt in the past 12 months, (5) had smoked 5 years or more in life, and f) had no intention to quit within 6 months (Bommelé et al., 2014, 2015a,b). We chose a definition that was most similar to most of the definitions that exist in the literature. This way, the results from our study could be compared to the findings of others. In line with previous research, we did not include participants younger than 25 years, because people under 25 may not have reached a stable cigarette consumption and may have less stable intentions regarding quitting (Emery, Gilpin, Ake, Farkas, \& Pierce, 2000). As people older than 65 are harder to recruit than younger people, we did not include people older than 65 years.

The screener questionnaire included the criteria above (including $\mathrm{t}_{0}$-measurements of cigarettes per day). It also assessed participants' sex and used their highest attained level of education to determine their socio-economic status (SES). Low SES participants had primary education, lower secondary education, lower vocational education, or middle vocational education. High SES participants had higher secondary education or tertiary education. Sex and education are important predictors of hardcore smoking (Emery et al., 2000; Ferketich et al., 2009). To control for potential biases due to these variables, we used a randomized stratification method (Suresh, 2011). Within each demographic group (i.e., low SES men, high SES men, low SES women, high SES women), participants were alternately allocated to one of the two conditions (i.e., the first low SES man received the experimental intervention, the second one the control intervention, the third one the experimental intervention). As participants could start the study at a time of their convenience, a near-random allocation to conditions was established within each stratified group. Participants were blinded to conditions other than their own. They completed the intervention in October 2014, and we collected follow-up data in November and December 2014. 
Bommelé, J., Schoenmakers, T.M., Kleinjan, M., Peters, G.J.Y., Dijkstra, A., Mheen, D. van de. Targeting hardcore smokers: the effects of an online tailored intervention, based on

motivational interviewing techniques. British Journal of Health Psychology: 2017, 22(3)

The ethics committee of the Faculty of Social Sciences at the Radboud University Nijmegen approved the study's protocol (ECG2013-1308-119a).

\section{Procedure}

Directly after the screener questionnaire $\left(\mathrm{t}_{0}\right), 1362$ hardcore smokers were allocated to one of the two conditions (intervention vs. control), stratified by sex and SES.

Of 1362 hardcore smokers allocated, 1090 signed informed consent and 931 completed the demographics $\left(\mathrm{t}_{0}\right)$. Please note that the baseline measurements $\left(\mathrm{t}_{0}\right)$ included both the screening questionnaire and the pre-intervention demographics. A total of 780 hardcore smokers completed the intervention itself and 757 finished the post-test measurements $\left(\mathrm{t}_{1}\right)$. Those who finished the post-test measurements were invited for follow-up. Participants completed one follow-up after 2 weeks $\left(\mathrm{t}_{2}\right.$ : $n=599)$ and one after 2 months $\left(t_{3}: n=519\right)$. Figure 1 shows the recruitment process throughout the study.

\section{[FIGURE 1]}

\section{Intervention}

The intervention (i.e., 'smoke experts.nl', in Dutch: 'rookexperts.nl') consisted of three components and took about $30 \mathrm{~min}$ to complete. We pre-tested the intervention for readability and comprehensibility in two focus groups among hardcore smokers. Throughout the intervention, participants were assisted by a virtual online character called 'Kees' (a common given name in the Netherlands). Kees represented himself as a digital trainer who was interested in the participants' opinion as smoke experts. Participants knew the trainer was not a real person. However, to make the digital trainer as realistic as possible, we showed several photographs of him throughout the intervention and composed the text in the intervention in such a way that it seemed as if he was interviewing the participants.

The first intervention component aimed to increase receptivity towards quitting. In this component, participants completed the kindness questionnaire (Reed \& Aspinwall, 1998), a self-affirmation task designed to tackle smokers' defensive responses to antismoking messages (Armitage \& Rowe, 2011; Bommelé et al., 2015b). The kindness questionnaire contains 10 items asking whether participants have ever performed acts of kindness to others (yes/no). We also asked to elaborate on some of these past acts of kindness.

The second intervention component aimed to increase intention to quit. Participants and the trainer discussed several smoking-related topics, such as the health effects of smoking, the effect of smoking on social relations, and the money potentially saved by quitting. With each topic, the trainer first assessed whether participants had dysfunctional beliefs about that topic by presenting a number of potential dysfunctional beliefs himself and asking participants to indicate whether they agreed with them or not. If they did, the trainer presented a text or video clip that countered specific those beliefs. As such, the trainer gave feedback that was tailored to the specific beliefs participants had. While discussing money, for example, the trainer asked participants who did not believe quitting would save money to calculate how much money they could save by quitting. He also asked them how they could spend that money. 
Bommelé, J., Schoenmakers, T.M., Kleinjan, M., Peters, G.J.Y., Dijkstra, A., Mheen, D. van de. Targeting hardcore smokers: the effects of an online tailored intervention, based on

motivational interviewing techniques. British Journal of Health Psychology: 2017, 22(3),

The third intervention component aimed to increase quitting self-efficacy.

Participants and the trainer discussed four general types of barriers to quitting: smoking-related habits, unsupportive others, stressful situations, and cravings. For each type, participants imagined they had quit smoking and encountered four specific situations. There were 16 situations in total. When discussing smoking-related habits, for example, participants discussed four situations in which smoking-related habits could lead to relapse: waking up, drinking coffee, having diner, and having a break. If participants indicated that remaining abstinent in one or more of those situations would be difficult, the trainer presented a video clip in which an ex-smoker explained how to deal with these specific situations. Previous studies have used similar 'tailored testimonials' before (McClure et al., 2014).

\section{Control intervention}

The control intervention was similar to the intervention layout and length, but contained bogus components. The first component did not include questions about kindness, but about everyday events (e.g., using public transport or reading a book). The second component did not discuss quitting smoking, but discussed the history of tobacco. The third component did not discuss barriers to quitting, but discussed the cultivation of tobacco. The control intervention included no tailored messages, no motivational interviewing techniques, and no self-affirmation manipulation.

\section{Demographics and main outcomes}

At the start of the experiment $\left(\mathrm{t}_{0}\right)$, we measured basic demographics (age, sex, education), smoking-related demographics (cigarettes per day, years smoked in life), and the Fagerström Test for Nicotine Dependence (Heatherton, Kozlowski, Frecker, \& Fagerström, 1991).

\section{Main outcomes}

We measured our main outcomes directly after the intervention $\left(t_{1}\right)$, after 2 weeks (first follow-up: $t_{2}$ ), and after 2 months (second follow-up: $t_{3}$ ). As the main outcomes were quite lengthy, we did not measure them at baseline $\left(\mathrm{t}_{0}\right)$. Including them at baseline would have increased dropout rates early in the study. Also, the responses given at baseline might have served as an anchor and would have influenced participants' answers on the post-test questions $\left(\mathrm{t}_{1}\right)$.

\section{Receptivity to quitting information}

Receptivity to information about quitting was measured with a four-item questionnaire. Example items were as follows: 'I am willing to think about smoking cessation', 'I would like to think carefully about smoking cessation', 'I would like to know more about smoking cessation', and 'Right now, I would like to read something about smoking cessation.'

\section{Intention to quit}

We measured intention to quit using a three-item questionnaire. The items were as follows: 'I intend to quit smoking someday', 'I will quit smoking in the future', and 'I will quit smoking someday'.

\section{Quitting self-efficacy}

We measured quitting self-efficacy using a three-item questionnaire. These items were as follows: 'I am able to quit smoking', 'I would be able to quit smoking', and 
Bommelé, J., Schoenmakers, T.M., Kleinjan, M., Peters, G.J.Y., Dijkstra, A., Mheen, D. van de. Targeting hardcore smokers: the effects of an online tailored intervention, based on

motivational interviewing techniques. British Journal of Health Psychology: 2017, 22(3)

'I could quit smoking'. Answers were given on a visual analogue scale ranging from 'completely disagree' to 'completely agree'. The computer program calculated the indicated position on the scale on a range from 1 to 100 . We used the same labels and scoring range to measure intention-to-quit measure and receptivity to quitting information.

\section{Stopcoach}

At each time point $\left(t_{1}, t_{2}\right.$ and $\left.t_{3}\right)$, we offered participants a web link to a subsequent smoking cessation intervention (iCoach) and asked whether they wanted to see that website (yes / no). iCoach is an online smoking cessation intervention developed by the European Commission (http://stopsmokingcoach.eu).

\section{Secondary outcomes}

\section{Cigarettes per day}

As smoking reduction may ultimately lead to smoking cessation (Carpenter, Hughes, Solomon, \& Callas, 2004; Hughes \& Carpenter, 2006), at baseline ( $\left.\mathrm{t}_{0}\right)$, and at each follow-up $\left(t_{2}\right.$ and $\left.t_{3}\right)$, we assessed the average number of cigarettes smoked daily. We calculated individual changes in cigarettes per day between $t_{0}$ and $t_{2}$, and between $t_{0}$ and $t_{3}$. We also calculated the percentage of participants who reduced their smoking by at least 1 cigarette per day and the percentage of participants who reduced their cigarette consumption by at least $50 \%$. We measured cigarettes per day before the experiment $\left(\mathrm{t}_{0}\right)$ and at each follow-up $\left(\mathrm{t}_{2}\right.$ and $\left.\mathrm{t}_{3}\right)$. Cigarettes per day is a variable that cannot change during a 30-min experiment, and we therefore assumed that the number of cigarettes per day directly post-experiment (t1) is the same as at baseline (t0).

\section{Quit attempts}

At each follow-up ( $t_{2}$ and $\left.t_{3}\right)$, we asked participants whether they had attempted to quit after the experiment (between $t_{1}$ and follow-up). If so, we asked whether they were still abstinent.

\section{Statistical analyses}

We compared post-test scores of the experimental intervention with those of the control intervention. We used ANCOVAs to test differences between condition in receptivity to quitting information, intention to quit, quitting self-efficacy, and cigarettes per day. All questionnaires were reliable at each time point (Cronbach's $\alpha>.90 ;$ GLB $>.95 ; \omega>.90)$. We used a chi-square test to test condition differences in Stopcoach visit and quit attempts. Suggested cut-off points for $\eta_{p}^{2}$ 's are .01, .06, and .14 for small, medium, and large effects (Cohen, 1988; Olejnik \& Algina, 2000). Before conducting the main analyses, we analysed whether selective dropout may have affected our results. We investigated whether those who had dropped out between $t_{0}$ and $t_{1}$ were different in sex, education, age, years smoked, nicotine dependence, and number of cigarette smoked per day from those who had not (i.e., 'completers'), and whether these differences were different between the two conditions. Between $\mathrm{t}_{0}$ and $\mathrm{t}_{1}$, dropouts were more likely to be male $(56.2 \%)$ than completers $(39.0 \%)$ in the experimental condition, $\chi^{2}(1, n=1,324)=19.51, p<.001$, $\varphi=.172$, while among controls, we found no significant difference (45.7\% vs. $49.2 \%), \chi^{2}(1, n=1,324)=.75, p=.386, \varphi=.034$. Also, dropouts in the experimental 
Bommelé, J., Schoenmakers, T.M., Kleinjan, M., Peters, G.J.Y., Dijkstra, A., Mheen, D. van de. Targeting hardcore smokers: the effects of an online tailored intervention, based on

condition smoked fewer cigarettes $(M=22.4, S D=7.0)$ than completers $(M=23.6$, $S D=8.6)$, while among controls, dropouts smoked more cigarettes $(M=22.3$, $S D=6.6)$ than completers $(M=21.8, S D=5.5)$. This interaction was significant,

$F(1,1,324)=4.85, p=.028, \quad=.004$. We therefore controlled the results, where possible, for sex and cigarettes per day.

\section{RESULTS}

\section{Sample characteristics}

Table 1 shows our sample characteristics. Among those who completed $\mathrm{t}_{1}$, we found no significant differences between conditions in age, $F(1,755)=.50, p=.481$, $\eta_{p}^{2}=.001$, sex, $\chi^{2}(1, N=757)=3.47, p=.062, \varphi=.068$, educational level, $\chi^{2}(1$, $n=757)=.02, p=.884, \varphi=.005$, in years smoked in life, $F(1,755)=.34, p=.559$, $\eta_{p}^{2}<.001$. However, those in the experimental condition were more nicotine dependent than controls, $F(1,755)=10.28, p=.001, \eta_{p}^{2}=.013$ and smoked more cigarettes per day, $F(1,754)=12.00, p<.001, \eta_{p}^{2}=.016$.

\section{[TABLE 1][FIGURE 1]}

Results for our main outcomes after the experiment $\left(\mathrm{t}_{1}\right)$, after 2 weeks $\left(\mathrm{t}_{2}\right)$, and after 2 months $\left(\mathrm{t}_{3}\right)$. Error bars reflect standard errors of the mean. ${ }^{\mathrm{a}}$ Controlled for age, sex, and cigarettes per day.

\section{Receptivity to quitting information}

At $t_{1}$, those in the experimental condition were significantly more receptive to information about quitting smoking than controls $(M=55.1, S D=26.1$ vs. $M=49.9$, $S D=25.4), F(1,753)=11.54, p=.001, \eta_{p}^{2}=.015$. This difference was no longer present at $\mathrm{t}_{2}, F(1,574)=3.00, p=.089, \eta_{p}^{2}=.005$, or at $\mathrm{t}_{3}, F(1,482)=.01, p=.971$, $\eta_{p}^{2}<.001$.

\section{Intention to quit}

We found no significant difference between conditions at $\mathrm{t}_{1}(M=63.5, S D=28.2$ vs. $M=60.3, S D=26.6), F(1,753)=3.43, p=.064, \eta_{p}^{2}=.005$. We also found no significant difference at $\mathrm{t}_{2}(M=62.6, S D=28.0$ vs. $M=61.4, S D=27.7), F(1$, $577)=.72, p=.397, \eta_{p}^{2}=.001$, or at $\mathrm{t}_{3}(M=61.9, S D=29.2$ vs. $M=65.2, S D=2.6)$, $F(1,489)=.85, p=.356, \eta_{p}^{2}=.002$.

\section{Quitting self-efficacy}

We found no significant difference between conditions at $\mathrm{t}_{1}(M=52.6, S D=26.5$ vs $M=52.6, S D=27.2), F(1,753)=.99, p=.321, \eta_{p}^{2}=.001$, at $t_{2}(M=52.1$, 
Bommelé, J., Schoenmakers, T.M., Kleinjan, M., Peters, G.J.Y., Dijkstra, A., Mheen, D. van de. Targeting hardcore smokers: the effects of an online tailored intervention, based on

$S D=25.9$ vs. $M=53.6, S D=25.9), F(1,576)<.01, p=.966, \eta_{p}^{2}<.001$, or at $\mathrm{t}_{3}$ $(M=53.3, S D=27.8$ vs. $M=57.5, S D=26.2), F(1,484)=1.22, p=.271, \eta_{p}^{2}=.003$.

\section{Stopcoach}

Those in the experimental condition did not request the web link significantly more often $(n=72,20.8 \%)$ than the controls $(n=75,18.2 \%)$ at $\mathrm{t}_{1}, \chi^{2}(1, N=757)=.79$, $p=.375, \varphi=.032$. We also found no significant difference between conditions at $\mathrm{t}_{2}$, $\chi^{2}(1, N=578)=.010, p=.920, \varphi=.004$, or at $t_{3}, \chi^{2}(1, N=485)=.79 p=.373$, $\varphi=.040$.

\section{Secondary outcomes}

\section{[FIGURE 3]}

Results for our secondary outcomes after the experiment $\left(\mathrm{t}_{1}\right)$, after 2 weeks $\left(\mathrm{t}_{2}\right)$, and after 2 months $\left(\mathrm{t}_{3}\right)$. Error bars reflect standard errors of the mean. ${ }^{\mathrm{a}}$ Controlled for age and sex.

\section{Cigarettes per day}

At $\mathrm{t}_{2}$, those in the experimental condition had significantly reduced their smoking $(M=-1.1, S D=6.2)$, while controls had not $(M=0.3, S D=3.5), F(1,596)=12.00$, $p=.001, \eta_{p}^{2}=.020$. Also, more participants in the experimental condition had reduced their smoking by at least 1 cigarette per day $(n=60,22.4 \%)$ than in the control group $(n=43,13.0 \%), \chi^{2}(1, n=599)=5.90, p=.015, \varphi=.124$. Similarly, more participants had reduced their cigarette consumption by at least $50 \%$ at $\mathrm{t}_{2}$ in the experimental group $(n=13,4.9 \%)$ than in the control group $(n=3,0.9 \%), \chi^{2}(1$, $n=599)=8.848, p=.003, \varphi=.122$. Although controls also had reduced their cigarette consumption at $\mathrm{t}_{3}$, the reduction in the number of cigarettes smoked was still significantly larger in the experimental condition $(M=-1.5, S D=5.1)$ than among controls $(M=-0.6, S D=5.0), F(1,516)=4.03, p=.045, \eta_{p}^{2}=.008$. Again, at $\mathrm{t}_{3}$, those in the experimental condition had reduced their smoking more often $(n=76$, $34.1 \%)$ than controls $(n=73,24.7 \%), \chi^{2}(1, n=519)=5.43, p=.020, \varphi=.107$. The group difference in the percentage of participants who had reduced their smoking by at least $50 \%$ at $\mathrm{t}_{3}$ was non-significant $(n=12,5.4 \%$ vs. $n=14,4.7 \%), \chi^{2}(1$, $n=519)=.113, p=.737, \varphi=.015$.

\section{Quit attempts}

At $t_{2}$, we found no significant difference in quit attempts between those in the experimental condition $(n=10,3.7 \%)$ and controls $(n=5,1.5 \%), \chi^{2}(1$, $n=599)=2.992, p=.084, \varphi=.071$, and we also found no such difference at $t_{3}$ $(n=11,4.9 \%$ vs. $n=14,4.7 \%), \chi^{2}(1, n=519)=.011, p=.915, \varphi=.005$. We found no significant difference in the number of abstinent participants at $\mathrm{t}_{2}(n=3,1.1 \%$ vs. $n=1,0.3 \%), \chi^{2}(1, n=599)=1.491, p=.222, \varphi=.050$ and no difference at $\mathrm{t}_{3}(n=3$, $1.3 \%$ vs. $n=4,1.4 \%), \chi^{2}(1, n=519)<.001, p=.995, \varphi<.001$. 
Bommelé, J., Schoenmakers, T.M., Kleinjan, M., Peters, G.J.Y., Dijkstra, A., Mheen, D. van de. Targeting hardcore smokers: the effects of an online tailored intervention, based on

motivational interviewing techniques. British Journal of Health Psychology: 2017, 22(3)

\section{DISCUSSION}

We tested a tailored, brief web-based intervention for hardcore smokers.

Immediately after the intervention, participants in the experimental condition seemed more open to information about quitting than controls. They also more often reduced their smoking by at least $50 \%$ than controls during the 2 weeks following the intervention. However, as participants only reduced their cigarette consumption by one cigarette per day, the clinical relevance is limited. The intervention proved to be ineffective at changing intention to quit, quitting self-efficacy, quit attempts, or willingness to visit a subsequent intervention.

\section{Receptivity towards information about quitting}

The first intervention component was a self-affirmation manipulation, designed to increase participants' receptivity towards information about smoking and quitting. Indeed, participants who completed the intervention were more receptive to quitting information than controls. This corroborates earlier research on this manipulation (Armitage, Harris, Hepton, \& Napper, 2008; Bommelé et al., 2015b).

Although the intervention increased receptivity to quitting information and reduced the number of cigarettes per day, it did not significantly change intention to quit. This is in line with findings from a recent meta-analysis on the efficacy of selfaffirmation manipulation (Epton, Harris, Kane, van Koningsbruggen, \& Sheeran, 2015b). The authors identified 144 experimental tests on the efficacy of selfaffirmation on message acceptance, intentions, and behaviour. They found that selfaffirmation increased message acceptance, intention and behaviour. However, the effect sizes for message acceptance and behaviour were larger than those for intention. Our intervention too had a larger effect on smoking behaviour $\left(\eta_{p}^{2}=.020\right)$ and openess to antismoking information $\left(\eta_{p}^{2}=.015\right)$ than on intention $\left(\eta_{p}^{2}=.005, \mathrm{~ns}\right)$. The fact that our results showed a similar pattern as those in the meta-analysis on self-affirmation manipulations suggests that the self-affirmation manipulation in our intervention might have been the most effective part of the intervention.

\section{Intention to quit and quitting self-efficacy}

The second and third intervention components aimed to increase intention to quit by increasing quitting self-efficacy and by challenging dysfunctional beliefs about smoking and quitting. We found no significant effects on intention to quit and quitting self-efficacy. Because our sample size was substantial, we can be fairly certain that our single-session intervention is not able to change these variables among hardcore smokers.

Future studies might combine this intervention with additional interventions components, such as face-to-face motivational interviews (Miller, 1983; Miller \& Rollnick, 2013). In such a case, the online and offline components may together increase intention and quitting self-efficacy, as smokers in the experimental condition did show an increased receptivity to information about quitting smoking.

\section{Reducing cigarette consumption}

Participants who completed the intervention had a higher average smoking reduction than controls and more of those in the experimental group reduced their cigarette consumption by at least $50 \%$ than among controls. However, the average smoking reduction in the experimental group was only 1 cigarette per day and only about $5 \%$ of those in the experimental group reduced their smoking by at least $50 \%$. These results are of limited clinical relevance and do not justify a large-scale 
Bommelé, J., Schoenmakers, T.M., Kleinjan, M., Peters, G.J.Y., Dijkstra, A., Mheen, D. van de. Targeting hardcore smokers: the effects of an online tailored intervention, based on

motivational interviewing techniques. British Journal of Health Psychology: 2017, 22(3)

implementation of the intervention in its current form. However, the results from this study may help develop future online interventions for hardcore smokers.

One possible explanation as to why the intervention did not increase intention and self-efficacy, while changing smoking behaviour to a small extent, might be that participating in an intervention about the pros and cons of smoking and smoking cessation changed other factors not measured in our study. The intervention might have made participants more aware of their own beliefs about smoking. This awareness could have been triggered when participants smoked in the weeks following the intervention. On other words, participants may have become more conscious about their cigarette consumption. If future interventions would combine elements from this intervention, it might also refer to those situations in which participants became aware of their cigarette consumption. However, additional research is needed to develop an intervention that would reduce cigarette consumption to clinically relevant level.

\section{Strengths and limitations}

One statistical challenge in our study has been the differences in cigarette consumption between the experimental group and the control group at baseline $\left(\mathrm{t}_{0}\right)$. Given the randomization procedure, this was not to be expected and it is therefore a matter of contingency. In our study, we first measured cigarettes per day in the screener questionnaire (assessing eligibility, $\mathrm{T}_{0}$ ), before randomly allocating participants to either the control or the experimental condition. None of the background variables measured before this randomization had any influence upon the condition the participants were allocated to. Also, our sample size should have been sufficient enough to prevent differences between conditions at baseline. Despite the fact that our randomization reduced the chance of having group differences at baseline to a minimum, such chance can never be ruled out completely. After finding the baseline differences, we controlled for cigarette consumption in every analysis possible and cancelled out effects that could potentially have been caused by the differences in cigarette consumption (and nicotine dependence) at baseline. Despite the fact that we controlled for age, sex, and cigarettes per day in each analysis, selective dropout may have biased our follow-up data. If in the future this intervention is tested in a randomized controlled trial as part of heath care practice, we believe intention-to-treat analyses are appropriate. For the present stand-alone test, overly conservative estimates due to intention-to-treat analyses might prematurely reject this potentially effective intervention.

A methodological challenge of our study is the fact that not all participants in the experimental condition received the same quality of self-efficacy enhancing information. This self-efficacy enhancing information was presented in a series of video clips in which an ex-smoker discussed specific ways to prevent relapse after quitting. Although the situations were the same for all participants, the actors in the video clips matched the participants' gender and socio-economic status. Men, for example, watched video clips of male actors, while women watched videos clips of female actors. As some actors may have been more credible than others, the video clips may not have been similarly convincing for all four subgroups.

A strength of our study is the use of a control intervention that was similar in design and layout to the experimental intervention. The only differences between the experimental condition and the control condition were the content and the combination of techniques used. In the experimental condition, we used tailored 
Bommelé, J., Schoenmakers, T.M., Kleinjan, M., Peters, G.J.Y., Dijkstra, A., Mheen, D. van de. Targeting hardcore smokers: the effects of an online tailored intervention, based on

motivational interviewing techniques. British Journal of Health Psychology: 2017, 22(3),

messages, motivational interviewing techniques, and a self-affirmation manipulation. We did not use these techniques in the control intervention. This way, we can be certain that the differences between conditions have been caused by this combination of techniques and content only (de Bruin, Crutzen, \& Peters, 2015; Peters, de Bruin, \& Crutzen, 2015).

\section{Practical implications}

While there are many web-based interventions available for smokers (Civljak et al., 2013; Walters et al., 2006), our intervention is, as far as we know, the first online intervention designed especially for hardcore smokers. Although the long-term effects of our intervention are unclear, it seems to increase receptivity to quitting information in the short term. It does not, however, increase hardcore smokers' selfefficacy or intention to quit.

Health professionals (e.g., GP's, physiotherapists, medical specialists) play an important role in tobacco control. They often encounter hardcore smokers and have shown to be able to effectively motivate some of these smokers to quit smoking (Omaña-Cepeda, Jane-Salas, Estrugo-Devesa, Chimenos-Kustner, \& Lopez-Lopez, 2015; Stead et al., 2013). However, few hardcore smokers are willing to quit smoking. Many health professionals are reluctant to discuss smoking cessation, because they fear it might damage their relationship with the patient (Coleman, Murphy, \& Cheater, 2000).

Our intervention may help both hardcore smokers and health professionals in such cases. Health care professionals could offer our intervention to hardcore smokers as an introduction to a next consult. These smokers then complete this intervention at home, before their next consult. As the current intervention does not require face-toface interaction with a health professional, smokers may feel less threatened by the antismoking information. After completing the intervention, smokers might have become more receptive for and willing to discuss smoking cessation during the next visit to the health professional. However, this increase in receptivity is only temporary and may not last much longer than a week. Psychotherapists, physiotherapists, and other health professionals who see their patients on a weekly or biweekly basis may use this intervention as a way to reduce hardcore smokers' defensive responses towards information about quitting. Health professionals who want to involve resistant hardcore smokers in tobacco control and who see their patients regularly could use this intervention as a low-cost introduction to a face-toface conversation about smoking cessation.

The intervention may be less suitable for patients of health professionals who do not see their patients regularly. If such health professionals would use this intervention as a standalone e-health intervention with little face-to-face support, the intervention is not expected to lead to clinically relevant changes in smoking. But as a tool for assisting health professionals in the short term, it might be helpful in reaching and involving resistant hardcore smokers in tobacco control.

\section{Final conclusions}

The intervention increases hardcore smokers' receptivity to information about quitting. It also helps to reduce smoking by about one cigarette per day. However, it proved to be ineffective at increasing hardcore smokers' quitting self-efficacy, intention to quit or quit attempts. The results therefore do not warrant an immediate large-scale implementation as a standalone intervention. However, future research 
Bommelé, J., Schoenmakers, T.M., Kleinjan, M., Peters, G.J.Y., Dijkstra, A., Mheen, D. van de. Targeting hardcore smokers: the effects of an online tailored intervention, based on

motivational interviewing techniques. British Journal of Health Psychology: 2017, 22(3),

might investigate ways health professionals could use this intervention as a first step to involve hardcore smokers in tobacco control.

\section{Author CONTRIBUTIONS}

All authors designed the study. JB, TS, and GJP conducted the statistical analysis. JB wrote the first draft of the manuscript, and all authors contributed to and have approved the final manuscript.

\section{FUNDING}

This article was supported by the Netherlands Organisation for Health Research and Development (ZonMW) grant 200120001. The sponsor had no influence on the design, data collection, analysis and interpretation of the data, nor in writing the article or the decision to submit for publication.

\section{CONFLICT OF INTEREST}

None to declare.

\section{Ancillary}

\section{REFERENCES}

Ajzen, I. (1991). The theory of planned behavior. Organizational Behavior and Human Decision Processes, 50, 179-211. https://doi-org.proxy.library.uu.nl/10.1016/07495978(91)90020-t

Armitage, C. J., Harris, P. R., Hepton, G., \& Napper, L. (2008). Self-affirmation increases acceptance of health-risk information among UK adult smokers with low socioeconomic status. Psychology of Addictive Behaviors: Journal of the Society of Psychologists in Addictive Behaviors, 22(1), 88-95. https://doi-org.proxy.library.uu.nl/10.1037/0893$164 \times .22 .1 .88$

Armitage, C. J., \& Rowe, R. (2011). Testing multiple means of self-affirmation. British Journal of Psychology, 102, 535-545. https://doi-org.proxy.library.uu.nl/10.1111/j.20448295.2010.02014.x

Bandura, A. (1977). Self-efficacy: Toward a unifying theory of behavioral change. Psychological Review, 84, 191-215. https://doi-org.proxy.library.uu.nl/10.1037/0033295x.84.2.191

Bartholomew, L. K., Parcel, G. S., \& Kok, G. (1998). Intervention mapping: A process for developing theory and evidence-based health education programs. Health Education \& Behavior, 25, 545-563. https://doi-org.proxy.library.uu.nl/10.1177/109019819802500502

Bartholomew, L. K., Parcel, G. S., Kok, G., Gottlieb, N. H., \& Fernández, M. E. (2011). Planning health promotion programs: An intervention mapping approach (3rd ed.). San Francisco, CA: Josey-Bass.

Bommelé, J., Kleinjan, M., Schoenmakers, T. M., Burk, W. J., Van Den Eijnden, R. J. J. M., \& Van de Mheen, D. (2015a). Identifying subgroups among hardcore smokers: A latent profile approach. PLoS ONE, 10(7), e0133570. https://doiorg.proxy.library.uu.nl/10.1371/journal.pone.0133570

Bommelé, J., Nagelhout, G. E., Kleinjan, M., Schoenmakers, T. M., Willemsen, M. C., \& Van de Mheen, $D$. (2016). Prevalence of hardcore smoking in the Netherlands between 2001 and 2012: A test of the hardening hypothesis. BMC Public Health, 16, 1-7. https://doiorg.proxy.library.uu.nl/10.1186/s12889-016-3434-x

Bommelé, J., Schoenmakers, T. M., Kleinjan, M., Peters, G.-J. Y., Das, E., Dijkstra, A., \& Van de Mheen, D. (2015b). Combining a self-affirmation manipulation and a self-efficacy manipulation: Could that improve intention to quit and its predictors among hardcore smokers? Under Review. 
Bommelé, J., Schoenmakers, T.M., Kleinjan, M., Peters, G.J.Y., Dijkstra, A., Mheen, D. van de. Targeting hardcore smokers: the effects of an online tailored intervention, based on

motivational interviewing techniques. British Journal of Health Psychology: 2017, 22(3), 644=66

Bommelé, J., Schoenmakers, T. M., Kleinjan, M., van Straaten, B., Wits, E., Snelleman, M., \& van de Mheen, D. (2014). Perceived pros and cons of smoking and quitting in hard-core smokers: A focus group study. BMC Public Health, 14(1), 175. https://doiorg.proxy.library.uu.nl/10.1186/1471-2458-14-175

Carpenter, M. J., Hughes, J. R., Solomon, L. J., \& Callas, P. W. (2004). Both smoking reduction with nicotine replacement therapy and motivational advice increase future cessation among smokers unmotivated to quit. Journal of Consulting and Clinical Psychology, 72, 371-381. https://doi-org.proxy.library.uu.nl/10.1037/0022-006X.72.3.371

Civljak, M., Stead, L. F., Hartmann-Boyce, J., Sheikh, A., \& Car, J. (2013). Internet-based interventions for smoking cessation. Cochrane Database of Systematic Reviews, 7(7), CD007078. https://doi-org.proxy.library.uu.nl/10.1002/14651858.CD007078.pub4

Cohen, J. (1988). Statistical power analysis for the behavioural sciences (2nd ed.). New York, NY: Academic Press.

Coleman, T., Murphy, E., \& Cheater, F. (2000). Factors influencing discussion of smoking between general practitioners and patients who smoke: A qualitative study. British Journal of General Practice, 50, 207-210

Costa, M. L., Cohen, J. E., Chaiton, M. O., Ip, D., McDonald, P., \& Ferrence, R. (2010). "Hardcore" definitions and their application to a population-based sample of smokers. Nicotine \& Tobacco Research: Official Journal of the Society for Research on Nicotine and Tobacco, 12, 860-864. https://doi-org.proxy.library.uu.nl/10.1093/ntr/ntq103

de Bruin, M., Crutzen, R., \& Peters, G.-J. Y. (2015). Everything should be as simple as possible, but this will still be complex: A reply to various commentaries on IPEBA. Health Psychology Review, 9(1), 38-41. https://doi-

org.proxy.library.uu.nl/10.1080/17437199.2014.981833

Emery, S., Gilpin, E. A., Ake, C., Farkas, A. J., \& Pierce, J. P. (2000). Characterizing and identifying "hard-core" smokers: Implications for further reducing smoking prevalence. American Journal of Public Health, 90, 387-394. https://doiorg.proxy.library.uu.nl/10.2105/AJPH.90.3.387

Epton, T., Harris, P. R., Kane, R., \& Van Koningsbruggen, G. M. (2015a). Health psychology the impact of self-affirmation on health-behavior change: A meta-analysis the impact of self-affirmation on health-behavior change. Health Psychology, 34(3), 187-196. https://doiorg.proxy.library.uu.nl/10.1037/hea0000116

Epton, T., Harris, P. R., Kane, R., van Koningsbruggen, G. M., \& Sheeran, P. (2015b). The impact of self-affirmation on health-behavior change: A meta-analysis. Health Psychology: Official Journal of the Division of Health Psychology, American Psychological Association, 34, 187-196. https://doi-org.proxy.library.uu.nl/10.1037/hea0000116

Ferketich, A. K., Gallus, S., Colombo, P., Pacifici, R., Zuccaro, P., \& La Vecchia, C. (2009). Hardcore smoking among Italian men and women. European Journal of Cancer Prevention, 18(2), 100-105. https://doiorg.proxy.library.uu.nl/10.1097/CEJ.0b013e32830c8d98

Fishbein, M., \& Ajzen, I. (2010). Predicting and changing behavior: The reasoned action approach. New York, NY: Psychology Press.

Friederichs, S. A., Oenema, A., Bolman, C., Guyaux, J., van Keulen, H. M., \& Lechner, L. (2014). I Move: Systematic development of a web-based computer tailored physical activity intervention, based on motivational interviewing and self-determination theory. BMC Public Health, 14(1), 212. https://doi-org.proxy.library.uu.nl/10.1186/1471-2458-14-212

Harris, P. R., \& Epton, T. (2009). The impact of self-affirmation on health cognition, health behaviour and other health-related responses: A narrative review. Social and Personality Psychology Compass, 3, 962-978. https://doi-org.proxy.library.uu.nl/10.1111/j.17519004.2009.00233.x

Harris, P. R., \& Epton, T. (2010). The impact of self-affirmation on health-related cognition and health behaviour: Issues and prospects. Social and Personality Psychology Compass, 4, 439-454. https://doi-org.proxy.library.uu.nl/10.1111/j.1751-9004.2010.00270.x

Heatherton, T. F., Kozlowski, L. T., Frecker, R. C., \& Fagerström, K. O. (1991). The fagerström test for nicotine dependence: A revision of the fagerström tolerance questionnaire. Addiction, 86, 1119-1127. https://doi-org.proxy.library.uu.nl/10.1111/j.13600443.1991.tb01879.x 
Bommelé, J., Schoenmakers, T.M., Kleinjan, M., Peters, G.J.Y., Dijkstra, A., Mheen, D. van de. Targeting hardcore smokers: the effects of an online tailored intervention, based on

motivational interviewing techniques. British Journal of Health Psychology: 2017, 22(3), 644-660

Hughes, J. R., \& Carpenter, M. J. (2006). Does smoking reduction increase future cessation and decrease disease risk? A qualitative review. Nicotine \& Tobacco Research: Official Journal of the Society for Research on Nicotine and Tobacco, 8, 739-749. https://doiorg.proxy.library.uu.nl/10.1080/14622200600789726

Jarvis, M. J., Wardle, J., Waller, J., \& Owen, L. (2003). Prevalence of hardcore smoking in England, and associated attitudes and beliefs: Cross sectional study. BMJ, 326, 1061. https://doi-org.proxy.library.uu.nl/10.1136/bmj.326.7398.1061

Lai, D. T., Cahill, K., Qin, Y., \& Tang, J.-L. (2010). Motivational interviewing for smoking cessation. Cochrane Database of Systematic Reviews, (1), CD006936. https://doiorg.proxy.library.uu.nl/10.1002/14651858.cd006936.pub2

Lemmens, V., Oenema, A., Knut, I. K., \& Brug, J. (2008). Effectiveness of smoking cessation interventions among adults: A systematic review of reviews. European Journal of Cancer Prevention: The Official Journal of the European Cancer Prevention Organisation (ECP), 17, 535-544. https://doi-org.proxy.library.uu.nl/10.1097/CEJ.0b013e3282f75e48

McClure, J. B., Peterson, D., Derry, H., Riggs, K., Saint-Johnson, J., Nair, V., ... \& Shortreed, S. M. (2014). Exploring the "active ingredients" of an online smoking intervention: A randomized factorial trial. Nicotine and Tobacco Research, 16, 1129-1139. https://doi-org.proxy.library.uu.nl/10.1093/ntr/ntu057

McQueen, A., \& Klein, W. M. P. (2006). Experimental manipulations of self-affirmation: A systematic review. Self and Identity, 5, 289-354. https://doi-

org.proxy.library.uu.nl/10.1080/15298860600805325

Miller, W. R. (1983). Motivational interviewing with problem drinkers. Behavioural

Psychotherapy, 11, 147-172. https://doi-

org.proxy.library.uu.nl/10.1017/S0141347300006583

Miller, W. R., \& Rollnick, S. (2013). Motivational interviewing. Helping people change (3rd ed.). New York, NY: The Guilford Press.

Olejnik, S., \& Algina, J. (2000). Measures of effect size for comparative studies: Applications, interpretations, and limitations. Contemporary Educational Psychology, 25, 241-286. https://doi-org.proxy.library.uu.nl/10.1006/ceps.2000.1040

Omaña-Cepeda, C., Jane-Salas, E., Estrugo-Devesa, A., Chimenos-Kustner, E., \& LopezLopez, J. (2015). Effectiveness of dentist's intervention in smoking cessation: A review. Journal of Clinical and Experimental Dentistry, 8(1), e78-e83. https://doiorg.proxy.library.uu.nl/10.4317/jced.52693

Peters, G.-J. Y., de Bruin, M., \& Crutzen, R. (2015). Everything should be as simple as possible, but no simpler: Towards a protocol for accumulating evidence regarding the active content of health behaviour change interventions. Health Psychology Review, 9(1), 1-14. https://doi-org.proxy.library.uu.nl/10.1080/17437199.2013.848409

Prochaska, J. O., \& DiClemente, C. C. (1982). Transtheoretical therapy: Toward a more integrative model of change. Psychotherapy: Theory Research \& Practice, 19, 276-288. https://doi-org.proxy.library.uu.nl/10.1037/h0088437

Prochaska, J. O., \& DiClemente, C. C. (1983). Stages and processes of self-change of smoking: toward an integrative model of change. Journal of Consulting and Clinical Psychology, 51, 390-395. https://doi-org.proxy.library.uu.nl/10.1037/0022-006X.51.3.390

Reed, M. B., \& Aspinwall, L. G. (1998). Self-affirmation reduces biased processing of health risk information. Motivation and Emotion, 22, 99-132. https://doi-

org.proxy.library.uu.nl/10.1023/A:1021463221281

Rosenstock, I. M., Strecher, V. J., \& Becker, M. H. (1988). Social learning theory and the health belief model. Health Education \& Behavior, 15, 175-183. https://doiorg.proxy.library.uu.nl/10.1177/109019818801500203

Shahab, L., \& McEwen, A. (2009). Online support for smoking cessation: A systematic review of the literature. Addiction, 104, 1792-1804. https://doiorg.proxy.library.uu.nl/10.1111/j.1360-0443.2009.02710.x

Sorg, A., Xu, J., Doppalapudi, S. B., Shelton, S., \& Harris, J. K. (2011). Hardcore smokers in a challenging tobacco control environment: The case of Missouri. Tobacco Control, 20, 388-390. https://doi-org.proxy.library.uu.nl/10.1136/tc.2010.039743

Stead, L. F., Buitrago, D., Preciado, N., Sanchez, G., Hartmann-Boyce, J., \& Lancaster, T. (2013). Physician advice for smoking cessation. In L. F. Stead (Ed.), Cochrane database of systematic reviews. Chichester, UK: John Wiley. 
Bommelé, J., Schoenmakers, T.M., Kleinjan, M., Peters, G.J.Y., Dijkstra, A., Mheen, D. van de. Targeting hardcore smokers: the effects of an online tailored intervention, based on

motivational interviewing techniques. British Journal of Health Psychology: 2017, 22(3), 644-66

Steele, C. M. (1988). The Psychology of Self-Affirmation: Sustaining the Integrity of the Self. In L. B. B. T.-A. in E. S. Psychology (Ed.), (Vol. Volume 21, pp. 261-302). Academic Press. https://doi-org.proxy.library.uu.nl/10.1016/s0065-2601(08)60229-4

Suresh, K. (2011). An overview of randomization techniques: An unbiased assessment of outcome in clinical research. Journal of Human Reproductive Sciences, 4(1), 8. https://doiorg.proxy.library.uu.nl/10.4103/0974-1208.82352

Vangeli, E., Stapleton, J., Smit, E. S., Borland, R., \& West, R. (2011). Predictors of attempts to stop smoking and their success in adult general population samples: A systematic review. Addiction, 106, 2110-2121. https://doi-org.proxy.library.uu.nl/10.1111/j.13600443.2011.03565.x

Walters, S. T., Wright, J. A., \& Shegog, R. (2006). A review of computer and Internet-based interventions for smoking behavior. Addictive Behaviors, 31, 264-277. https://doiorg.proxy.library.uu.nl/10.1016/j.addbeh.2005.05.002

Warner, K., \& Burns, D. (2003). Hardening and the hard-core smoker: Concepts, evidence, and implications. Nicotine \& Tobacco Research, 5(1), 37-48. https://doiorg.proxy.library.uu.nl/10.1080/1462220021000060428

WHO (2011). WHO Rapport on the global tobacco epidemic, 2011 Warning about the dangers of tobacco. Geneva, Switzerland: Author.

\section{TABLES AND FIGURES}

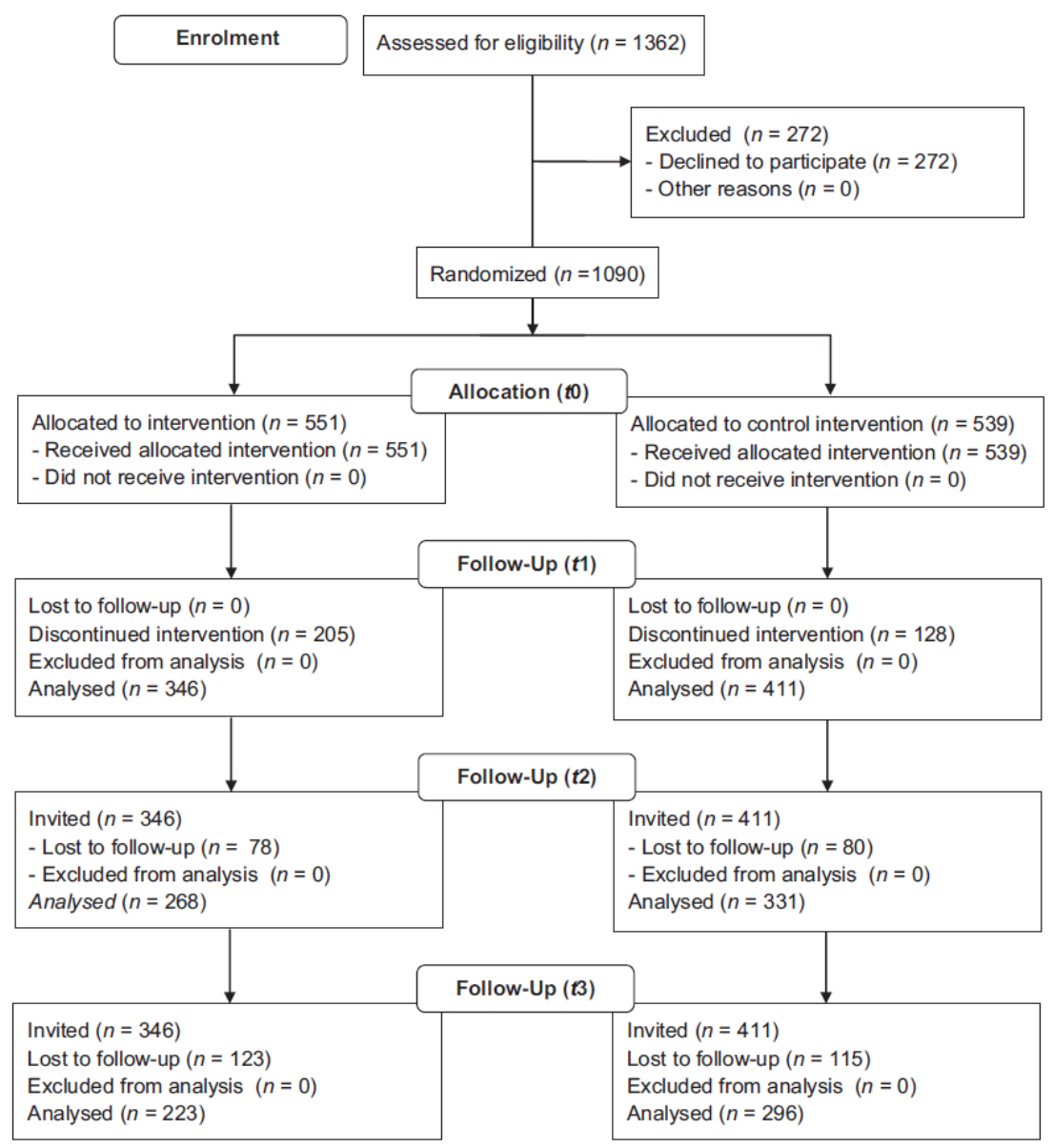

Figure I. Flow diagram of recruitment and progress throughout the study. 
Bommelé, J., Schoenmakers, T.M., Kleinjan, M., Peters, G.J.Y., Dijkstra, A., Mheen, D. van de. Targeting hardcore smokers: the effects of an online tailored intervention, based on

Table I. Sample characteristics at $t_{1}$

\begin{tabular}{|c|c|c|c|}
\hline & Intervention & Controls & Significance \\
\hline Sample size & 346 & 411 & \\
\hline Age (SD) & $49.0(10.4)$ & $48.5(10.3)$ & $p=.481$ \\
\hline \multicolumn{4}{|l|}{ Sex } \\
\hline Male & I 35 (39.0\%) & $183(44.5 \%)$ & \multirow[t]{2}{*}{$p=.062$} \\
\hline Female & $211(61.0 \%)$ & $228(55.5 \%)$ & \\
\hline \multicolumn{4}{|l|}{ Education } \\
\hline Low & $256(74.0 \%)$ & $306(74.5 \%)$ & \multirow[t]{2}{*}{$p=.884$} \\
\hline High & $90(26.0 \%)$ & 105 (25.5\%) & \\
\hline Years smoked in life (SD) & $31.9(11.1)$ & $31.4(10.9)$ & $p=.559$ \\
\hline Nicotine dependence $(S D)^{\mathrm{a}}$ & $6.1(1.8)$ & $5.6(1.8)$ & $p=.001$ \\
\hline Cigarettes per day & $23.6(8.6)$ & $21.8(5.5)$ & $p=.001$ \\
\hline
\end{tabular}

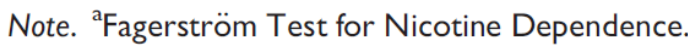

Figure 2. Results for our main outcomes after the experiment (t1), after 2 weeks (t2), and after 2 months ( $\mathrm{t} 3$ ). Error bars reflect standard errors of the mean. aControlled for age, sex, and cigarettes per day.
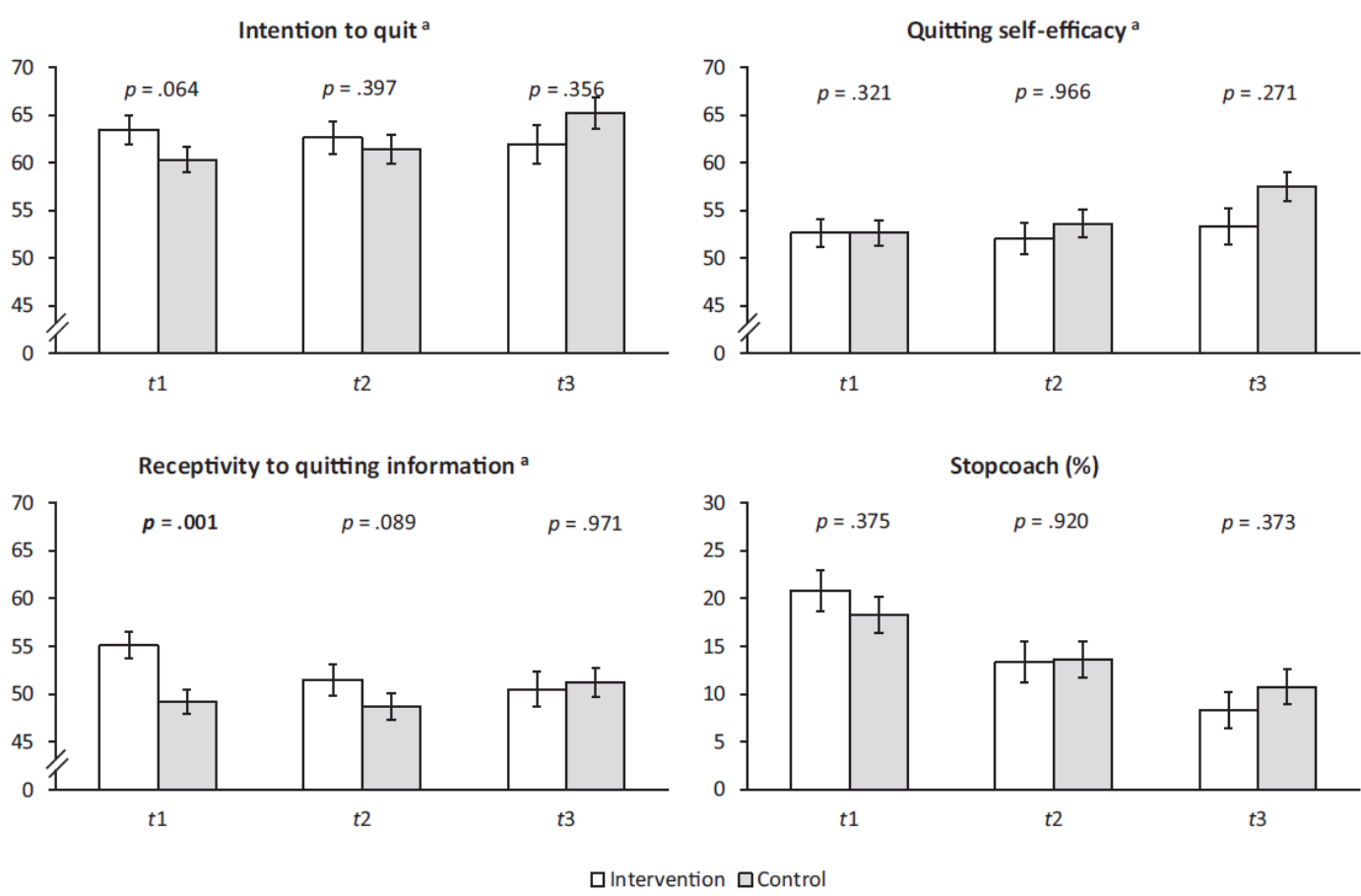
Bommelé, J., Schoenmakers, T.M., Kleinjan, M., Peters, G.J.Y., Dijkstra, A., Mheen, D. van de. Targeting hardcore smokers: the effects of an online tailored intervention, based on

motivational interviewing techniques. British Journal of Health Psychology: 2017, 22(3), 644-660

Figure 3. Results for our secondary outcomes after the experiment ( $\left.\mathrm{t}_{1}\right)$, after 2 weeks ( $\left.\mathrm{t}_{2}\right)$, and after 2 months ( $\left.\mathrm{t}_{3}\right)$. Error bars reflect standard errors of the mean. aControlled for age and sex.

Cigarettes per day

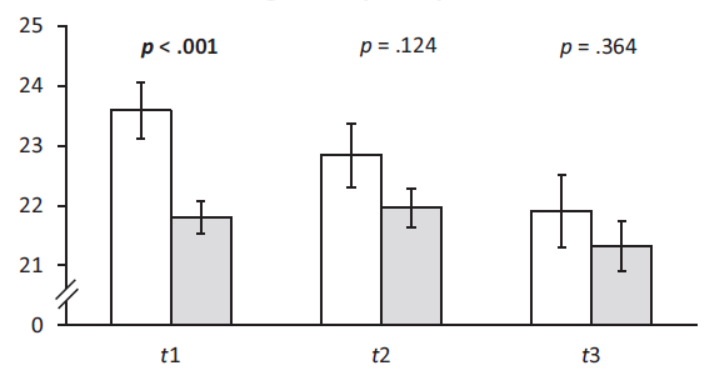

Quit attempts (\%)

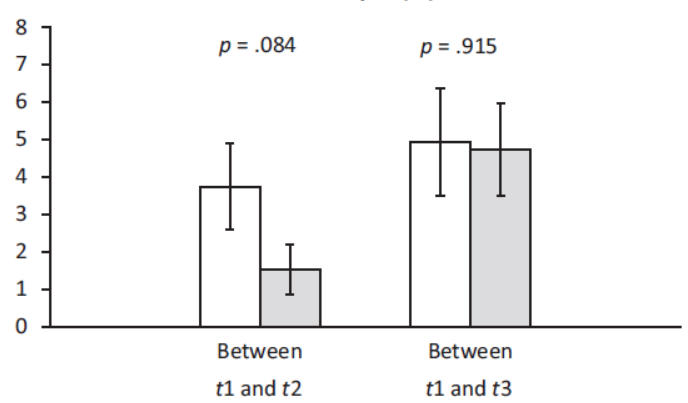

Change in cigarettes per day

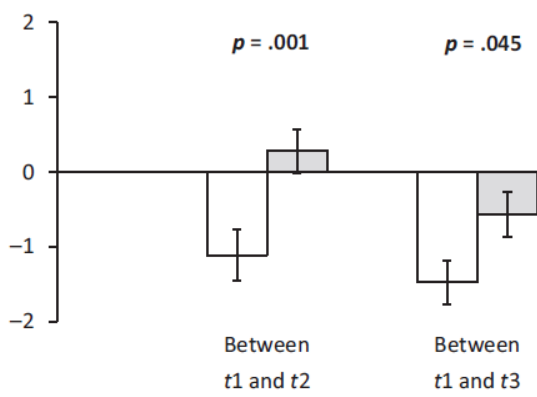

Quit Smoking (\%)
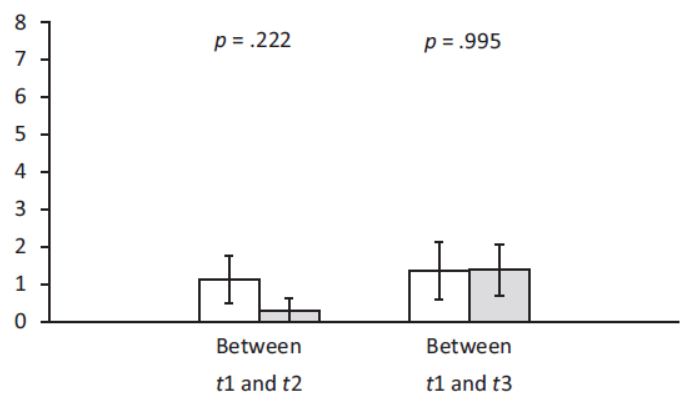

口Intervention $\square$ Control 